ESTUdos RBEP

\title{
Design educacional e material didático impresso para educação a distância: um breve panorama
}

\author{
Bruna Damiana de Sá Sólon Heinsfeld ${ }^{\mathrm{I}, \text { II }}$ \\ Ana Lucia Pena ${ }^{\text {III, IV }}$
}

http://dx.doi.org/10.24109/2176-6681.rbep.98i250.3042

\footnotetext{
Fundação Centro de Ciências e Educação Superior a Distancia do Estado do Rio de Janeiro (Cecierj), Rio de Janeiro, Rio de Janeiro, Brasil. E-mail: <brunadamiana@ gmail.com>; $\quad<$ http://orcid. org/0000-0003-1824-7282>.

II Mestranda em Educação pela Pontifícia Universidade Católica do Rio de Janeiro (PUC-RJ), Rio de Janeiro, Rio de Janeiro, Brasil.

III Centro Universitário de Caratinga (Unec), Caratinga, Minas Gerais, Brasil. E-mail: <lucia.anapena@ gmail.com>; <http://orcid. org/0000-0003-0513-5441>.

Iv Mestre em Educação e Linguagem pelo Centro Universitário de Caratinga (Unec), Caratinga, Minas Gerais, Brasil.
}

\section{Resumo}

No contexto da educação a distância, o material didático impresso (MDI) constitui uma das principais mídias utilizadas no processo de ensino e aprendizagem no Brasil. Contudo, também figura como um dos mecanismos didáticos com piores índices nas avaliações discentes. A partir dessas questões, analisa-se o desenvolvimento do MDI, com base no estudo do corpus, investigando as nuances do design educacional e seus componentes: objetivos de aprendizagem, seções temáticas, atividades, linguagem e imagens. Ratificando a análise, obtêm-se as impressões dos alunos usuários do material acerca desses elementos, a partir de questionário estruturado. Os trabalhos de Barreto et al. (2007), Barreto (2012), Filatro (2009), Filatro e Cairo (2015) e Preti (2010) são utilizados como subsídios teóricos relacionados ao design educacional. Embora demande adequações aos estudos recentes, o corpus selecionado se mostrou satisfatório quanto à experiência de aprendizagem.

Palavras-chave: educação a distância; design educacional; material didático impresso. 


\section{Abstract \\ Instructional design and the printed teaching material for distance education: a brief overview}

In Brazilian distance education, printed teaching materials are one of the primary media used in the teaching-learning process. However, they are also one of the worst-rated pedagogical mechanisms in students' evaluations. Hence, the development of these materials is analyzed, based in the study of a corpus, through the nuances of the instructional design and its components: learning objectives, thematic sections, activities, language and images. To confirm the analysis, a structured questionnaire was used to gather students' impressions on the material, in view of the aforementioned components. As theoretical basis on instructional design, it was employed the views of Barreto et al. (2007), Barreto (2012), Filatro (2009), Filatro and Cairo (2015) and Preti (2010). In conclusion, although the analyzed material requires adjustments to match the most recent studies, the selected corpus proved satisfactory with respect to the learning experience.

Keywords: distance education; instructional design; printed teaching material

\section{Introdução}

No decorrer da história da educação, o material didático de base textual conquistou o status de um dos pilares do processo de ensino e aprendizagem, sendo, década após década, extensamente adotado por escolas e instituições de formação livre.

Embora marcada por alterações de paradigmas e implementações de novas tecnologias, a pedagogia moderna ainda confia ao material didático textual grande responsabilidade, conferindo a ele não somente funções instrumentais, mas ideológicas, culturais e políticas, relacionadas também à formação do indivíduo como cidadão, seja esse material impresso ou disponibilizado digitalmente. Na educação a distância (EaD), além dessas atribuições, o material didático tem seu papel consagrado graças a seu potencial como ferramenta de ampliação do acesso à educação, favorecendo a inclusão, a democratização do saber e a promoção da autonomia do aluno.

Partindo dessa reflexão, enfatiza-se a necessidade de estudos sobre a concepção e o desenvolvimento desse tipo de material que, para fins desta pesquisa, será doravante indicado como material didático impresso (MDI), independentemente do suporte midiático pelo qual é veiculado. Assim sendo, o presente trabalho analisa a construção do MDI, transitando pelos aspectos do design educacional, apoiado em pesquisas teóricas de referência na área.

Assim como a EaD teve diversos avanços teóricos, metodológicos e tecnológicos, também o MDI sofre várias mudanças. De acordo com o 
Anuário Brasileiro Estatístico de Educação Aberta e a Distância (2007), o material impresso foi, então, a mídia mais utilizada na modalidade a distância no Brasil, chegando a 86,4\% do total.

Em 2014, os dados do Censo EAD.BR confirmaram a manutenção dessa preferência: de 254 instituições brasileiras de $\mathrm{EaD}$ respondentes à pesquisa, os "livros eletrônicos e outros textos digitais" ficam em primeiro lugar no somatório e individualmente por tipo de curso (Abed, 2015, p. 98).

Notadamente, o MDI figura como referencial da EaD, apresentando-se como uma das principais mídias pelas quais os alunos interagem com novos conhecimentos durante seus estudos formais (Barreto et al., 2007). Outrossim, o material didático carrega diversas nuances em sua construção: como texto, traz em si o discurso (Fiorin, 2007), que se apresenta traduzido nas concepções pedagógicas, na linguagem utilizada e nos conteúdos escolhidos; traz os recursos educacionais utilizados, a arquitetura de sua informação, as imagens selecionadas e as atividades.

Entende-se que esse material constitui um recurso de socialização do conhecimento, de dialogicidade e de interação entre aluno, informação e aprendizagem. Por esse viés, há a necessidade de se conceber estudos e entendimentos sobre as concepções e as linguagens veiculadas nessa mídia. Afinal, MDI não significa apenas uma entrega de conteúdo e/ ou o fazer teórico de uma disciplina. Implica formação, concebida com autonomia, para que diferentes sujeitos, com diversas origens, histórias de vida e inteligências possam construir com plenitude uma aprendizagem significativa.

\section{Material didático impresso para EaD: desafios e possibilidades}

Atualmente, pesquisadores e cientistas da educação têm clareza acerca da importância dos estudos sobre os materiais didáticos impressos utilizados em cursos de formação. Conforme Damiana e Pena (2016), se até a década de 1980 as pesquisas se detinham em questionar a ideologia veiculada nesses materiais, hoje são destinadas aos mais diversos tipos de investigação, graças ao rompimento com a crença de que o material didático constitui apenas um apanhado de valores da ortodoxia vigente. Emergiram à discussão as mediações que ocorrem entre material e atores envolvidos no processo de ensino e aprendizagem.

Choppin (2004) destaca que, historicamente, os materiais didáticos exercem quatro funções basilares, que variam quanto ao ambiente sociocultural e à época em que estão inseridos, às disciplinas e aos níveis de ensino, aos métodos e às formas de utilização: função referencial, função instrumental, função ideológica e cultural e função documental.

Trazendo a discussão para o âmbito da $\mathrm{EaD}$, pode-se dizer que o material didático, especificamente a mídia impressa para essa modalidade (apostilas, livros, cadernos didáticos, incluindo os digitais, passíveis de impressão), é um campo vasto de análise, compondo um dos processos relativos ao planejamento e à implementação da $\mathrm{EaD}$, com finalidade de 
"facilitar a construção do conhecimento e mediar a interlocução entre estudante e professor" (Brasil. MEC, 2007, p. 13). O MDI para EaD é "um texto dialógico, uma aula expositiva em forma textual, escrita de maneira estruturada para ser apreciada como texto, quer seja apresentada em suporte físico, quer em eletrônico" (Trimer, 2012, p. 314).

Embora, ao se falar de educação a distância, a lembrança das tecnologias digitais sejam acionadas quase automaticamente, cabe lembrar que em diversas localidades, em especial no interior do País, o acesso às mídias digitais e à rede de computadores ainda é escasso, sendo o MDI um suporte de extrema valia para os alunos.

A especificidade do MDI para a EaD [...] não está apenas no design, em seu aspecto didático, mas também no papel político do grupo que assume a empreitada da produção deste material, tendo em vista sua proposta de formação de determinado profissional. (Preti, 2010, p. 19).

Assim, o MDI centra-se na aprendizagem, que "é o processo pelo qual o indivíduo transforma informação em conhecimento" (Belisário, 2013, p. 230). Para que o MDI consiga tal intento, precisa constituir-se de elementos motivadores, reflexivos, dialógicos e, ao mesmo tempo, conectados às políticas ideológicas do contexto no qual o curso se insere. Tal estrutura se consegue conciliando as informações em uma arquitetura que privilegie a autonomia do aluno, sendo o MDI elaborado de forma adequada ao aprendizado a distância e preparado para distribuições midiáticas diversas.

É evidente, pois, que o material precisa revestir-se de algumas características específicas. Preti (2010), nesse sentido, menciona que, do ponto de vista do texto, dois aspectos precisam ser considerados: linguagem clara e precisa, de modo a estabelecer um diálogo com o aprendiz, e utilização de recursos visuais, como quadros, tabelas e sumários, facilitando a compreensão, permitindo a reflexão e estimulando o interesse do aluno. Trimer (2012) pontua, ainda, que o desenvolvimento do material que combine conteúdo, abordagem dialógica e aprofundamento teórico é um dos desafios do MDI para a EaD. Adiante, serão detalhados alguns desses elementos e estratégias.

\section{O processo de design educacional}

Atenção especial deve ser voltada à forma de construção do material didático para a $\mathrm{EaD}$, garantindo unidade entre os conteúdos, cobrindo-os de forma sistemática e organizada (Brasil. MEC, 2007, p. 15). Por trás dessa organização, há o que se convencionou chamar de arquitetura da informação, que consiste na maneira como as informações são disponibilizadas no material, combinando a organização dos conteúdos e a criação de uma interface que propicie a navegação fluida entre eles e, também, as possibilidades de desdobramento e interações com outras informações e outras mídias (Barreto, 2012).

Destaca-se, nesse momento, o design educacional, essencial no desenvolvimento do MDI, que contempla não somente o trabalho com a 
arquitetura da informação, mas também o revestimento do material de linguagem comunicacional e pedagógica (Preti, 2010, p. 50) e a aplicação de recursos educacionais para que o aluno possa aprender os conteúdos, além de desenvolver o pensamento crítico. Indo além, esse processo envolve também:

[...] planejamento, o desenvolvimento e a aplicação de métodos, técnicas, atividades, materiais, eventos e produtos educacionais em situações didáticas específicas, a fim de promover, a partir dos princípios de aprendizagem e instrução conhecidos, a aprendizagem humana. (Filatro, 2009, p. 3).

Para que o resultado final seja eficiente e satisfatório, o processo de design educacional deve englobar desde a concepção mais ampla do material, caminhando pelo plano da filosofia educacional, das teorias de aprendizagem e dos projetos político-pedagógicos dos programas educacionais, até o nível mais específico e concreto, como o refinamento das unidades de estudo, o texto didático do material ou mesmo a elaboração de atividades (Barreto et al., 2007; Filatro, 2009; Filatro; Cairo, 2015).

O processo de design educacional envolve a análise contextual, que "consiste em examinar a dinamicidade entre os diferentes níveis contextuais a fim de identificar as necessidades ou os problemas de aprendizagem, caracterizar o público-alvo e levantar as restrições técnicas, administrativas e culturais" (Filatro, 2009, p. 36), aprofundando o entendimento do problema educacional e dos objetivos a serem empreendidos. Filatro e Cairo (2015) reforçam que, por meio do planejamento e da coleta e avaliação de dados da análise contextual, as necessidades de aprendizagem são aclaradas, além de levantadas potencialidades e restrições, tanto do contexto de produção do material quanto de sua utilização.

Há especificidades a serem consideradas por toda a equipe de desenvolvimento do MDI para $\mathrm{EaD}$, cabendo reforçar que esse perfil do material não deve fazer as vezes de um livro-texto ou de um artigo científico: deve funcionar como uma verdadeira aula a distância. É necessário que o produto final seja capaz de refletir tudo aquilo que constaria em uma aula presencial; capaz de ensinar, além de verter conteúdos importantes de leitura (Barreto et al., 2007).

Com isso, verifica-se que o processo de design educacional para a EaD é complexo, e devem ser levados em consideração diversos princípios pedagógicos, entre eles os desenvolvidos por Barreto et al. (2007) em sua obra: coerência entre objetivos de aprendizagem e abordagem pedagógica utilizada; contextualização do conteúdo; ênfase na formação e no desenvolvimento de competências; estímulo à autonomia; aprendizagem significativa; metas e critérios claros de avaliação; uso de exemplos e analogias para facilitar o entendimento; uso de suporte visual e imagético e de linguagem adequada ao público-alvo. Dito isso, planejamento e análise dos elementos que dialogam com o design educacional são não somente salutares, como necessários ao processo de ensino e aprendizagem. 


\section{O design educacional em perspectiva: uma análise de corpus}

Ao considerar a elaboração de quaisquer materiais pedagógicos - seja em dimensão macro, como a curricular, ou micro, como objetos de aprendizagem -, há quatro questões fundamentais que precisam ser respondidas pelo material: que propósitos educacionais estão sendo buscados; que experiências educacionais permitem que esses objetivos sejam alcançados; qual a organização mais eficiente dessas experiências; e de que forma é possível verificar se os objetivos propostos estão sendo alcançados (Filatro; Cairo, 2015, p. 15).

Com base nessas perguntas e nos estudos sobre o desenvolvimento dos MDIs, serão descritos e analisados brevemente determinados elementos desse processo, colocando em perspectiva os traços do design educacional: unidades temáticas, objetivos, atividades de aprendizagem, boxes de elementos periféricos, linguagem e imagens e recursos gráficos.

Para esta pesquisa, foi analisado o livro didático Geografia da População (Dantas; Morais; Fernandes, 2011), da disciplina Dinâmica Populacional, ofertada no $4^{\circ}$ módulo da licenciatura em Geografia, oferecida pela Universidade Federal de Ouro Preto (Ufop). O MDI em questão, produzido pela Universidade Federal do Rio Grande do Norte (UFRN), em parceria com a Universidade Aberta do Brasil (UAB), foi idealizado para ser utilizado em conjunto com atividades on-line, como fóruns de discussão e videoaulas, disponibilizadas no ambiente virtual de aprendizagem do curso.

Buscando adquirir informações sobre o perfil do público-alvo ao qual o material foi destinado e coletar informações sobre as impressões desses alunos acerca do MDI, enviou-se um questionário eletrônico estruturado, de adesão voluntária, aos 15 alunos do polo de Ipatinga, Minas Gerais, que utilizaram o material em seus estudos. Foram obtidos 9 (60\%) respondentes como população total da pesquisa. Desse total, a maioria não possuía experiência prévia com a modalidade a distância da educação $(88,9 \%)$.

As questões referentes às características do material e às impressões dos alunos com relação ao seu uso tiveram o intuito de complementar quantitativamente, retificando ou ratificando, a análise feita do material, de aporte qualitativo. O questionário foi dividido em seis eixos: interação dentro dos textos; linguagem utilizada no material; conteúdo das unidades; recursos dentro das unidades; atividades; tratando da aprendizagem. Frisa-se que o interesse, aqui, é relacionar os recursos educacionais encontrados no corpus da análise às teorias pedagógicas e às recomendações encontradas na literatura especializada sobre MDI, discutindo a eficácia de cada um deles no processo de ensino e aprendizagem.

\section{Unidades didáticas}

De acordo com Preti (2010), as unidades, para que sejam consideradas didáticas, devem preencher alguns requisitos necessários ao processo de ensino e aprendizagem, sendo os quatro principais: objetivos, conteúdo, 
atividades e avaliação. O autor também recomenda que sejam abordados de dois a três temas principais em uma unidade didática, divididos em seções temáticas, e que cada unidade contenha três ou quatro objetivos. Por sua vez, cada seção deve possuir em torno de cinco páginas cada uma, estando relacionada a um ou dois objetivos específicos, contendo, pelo menos, uma atividade de estudo.

O livro Geografia da População (Dantas; Morais; Fernandes, 2011) possui, em formato digital, 254 páginas, estando dividido em 12 unidades didáticas, denominadas "aulas". Contendo em média 20 páginas, cada aula se encontra subdividida em: apresentação, objetivos, seções temáticas, resumo, autoavaliação, referências e anotações. Cada seção temática conta, ainda, com atividades, boxes de elementos periféricos e recursos gráficos diversos. O Quadro 1, a seguir, particulariza alguns dos elementos constituintes das unidades didáticas do MDI em questão, a partir dos requisitos relacionados por Preti (2010).

\section{Quadro 1 - Detalhamento das Unidades Didáticas do Material Geografia da População}

\begin{tabular}{|c|c|c|c|c|}
\hline Aula & Seções & Objetivos & Atividades & Páginas \\
\hline 1 & 5 & 4 & 4 & 18 \\
\hline 2 & 5 & 3 & 3 & 16 \\
\hline 3 & 3 & 4 & 3 & 18 \\
\hline 4 & 4 & 4 & 3 & 16 \\
\hline 5 & 5 & 3 & 3 & 24 \\
\hline 7 & 4 & 4 & 3 & 18 \\
\hline 8 & 5 & 4 & 3 & 22 \\
\hline 10 & 6 & 5 & 4 & 28 \\
\hline 11 & 4 & 4 & 4 & 20 \\
\hline 12 & 4 & 5 & 4 & 24 \\
\hline
\end{tabular}

Fonte: Elaboração própria.

Como é possível observar no Quadro 1, em 6 das 12 aulas, há mais seções temáticas do que objetivos propostos, abrindo uma lacuna para duas hipóteses: a existência de seções cuja separação temática não corresponde diretamente aos objetivos citados e a existência de mais de uma seção temática para cada objetivo. 
Buscando ampliar a investigação, foram distribuídas aos alunos algumas perguntas a respeito dos conteúdos das unidades didáticas. Com relação à quantidade de conteúdo apresentada em cada unidade, questionou-se se ela foi satisfatória, podendo ser considerada insatisfatória a quantidade reduzida ou a demasiada. Cinco dos nove alunos entenderam esse quesito como satisfatório (55,6\% das respostas). Porém, como o universo de sujeitos é pequeno, bastaria um ter apresentado opinião diferente para que o resultado fosse invertido, permitindo inferir a existência de problema nesse quesito e a necessidade de investigação mais aprofundada a respeito. Ao contrastar essa informação com a resposta dos alunos à indagação acerca da relação entre objetivos e temas das unidades, em que $88,9 \%$ dos alunos afirmaram haver conexão clara entre eles, reforça-se a ideia de haver lacuna de correspondência entre os elementos.

Com amparo nesses resultados, foi feito levantamento contrastando a temática e o conteúdo de cada uma das seções com os objetivos propostos no início de cada unidade didática. O Gráfico 1 apresenta os dados obtidos quanto ao número de objetivos contemplados pelo conteúdo das seções, enquanto o Gráfico 2 mostra quantas seções estão diretamente relacionadas a algum dos objetivos listados.

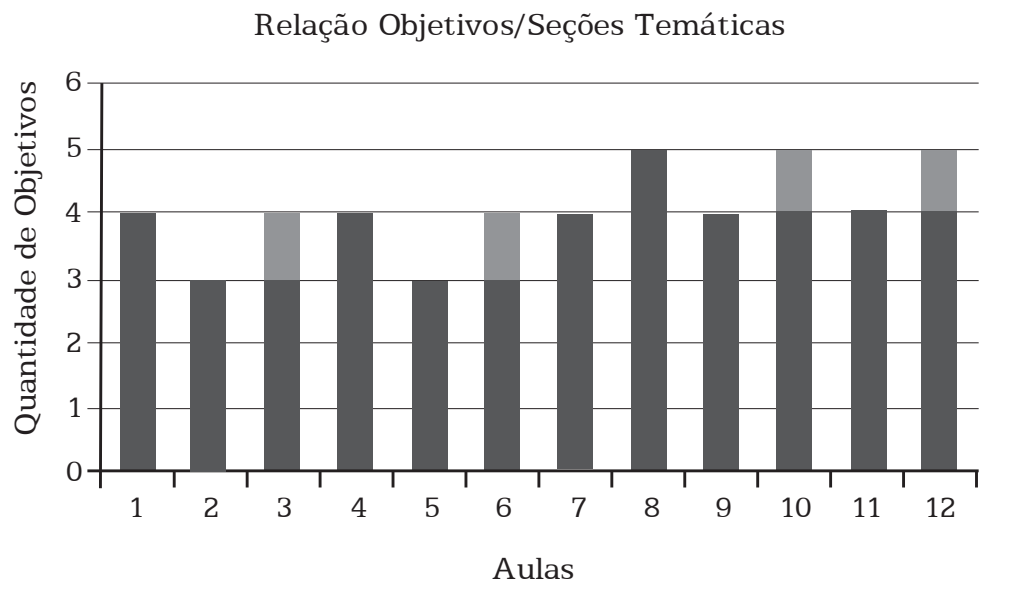

- Quantidade de objetivos contemplados pelas seções temáticas

- Quantidade de objetivos não contemplados pelas seções temáticas

\section{Gráfico 1 - Objetivos Contemplados e Objetivos não Contemplados pelas Seções Temáticas}

Fonte: Elaboração própria.

O Gráfico 1 mostra que, entre os 49 objetivos (100\%), apenas 4 (8\%) não foram diretamente contemplados pelos conteúdos apresentados nas seções temáticas (aulas 3, 6, 10 e 12). Entretanto, não se pode afirmar que os objetivos em questão deixaram de ser abrangidos na totalidade do material: uma das possibilidades verificadas é o objetivo estar sendo contemplado mediante atividade, autoavaliação ou proposta de pesquisa para o aluno, sendo esse um resultado satisfatório. 


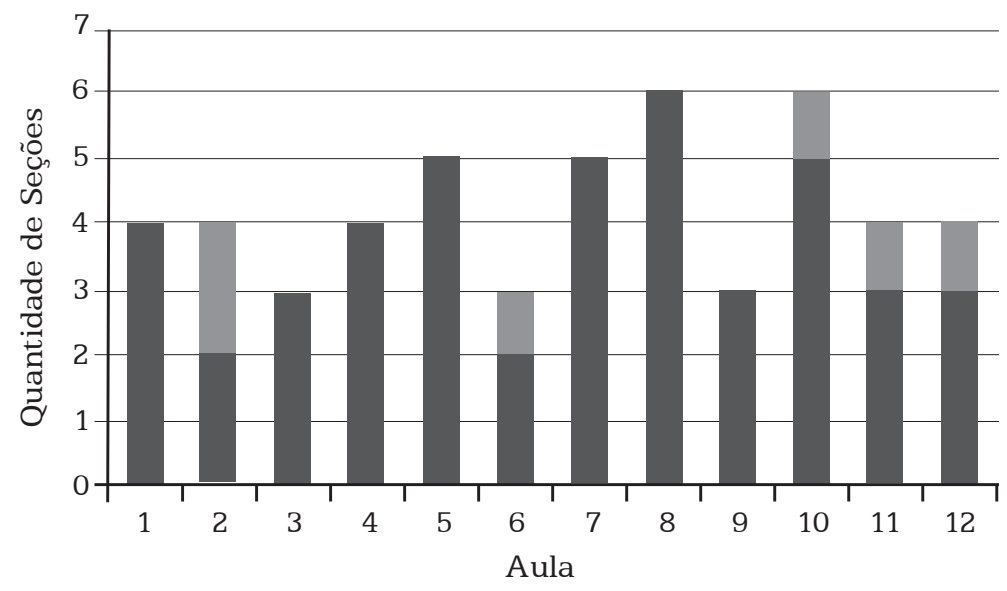

- Quantidade de seções relacionadas aos objetivos

Q Quantidade de seções não relacionadas aos objetivos

\section{Gráfico 2 - Seções Temáticas Diretamente Relacionadas aos Objetivos de Cada Unidade Didática}

Fonte: Elaboração própria.

No que diz respeito à relação entre seções temáticas e objetivos, perceberam-se dois casos distintos: a) embora cada uma das unidades didáticas tenha como introdução uma seção à parte, chamada "Apresentação", em alguns casos a seção temática subsequente atuou também como introdução ao tema principal da unidade, não favorecendo o alcance de quaisquer dos objetivos listados na aula (aulas 2, 6 e 10); e b) a ocorrência de seções temáticas cujo conteúdo extrapolou a aula e que, apesar de associado ao tema principal, não se relaciona diretamente a quaisquer dos objetivos listados (aulas 11 e 12).

Visando ao aprofundamento da análise, adicionou-se, ainda, a informação de quantas atividades estão presentes em cada seção, com base na recomendação de Barreto et al. (2007), de que cada seção temática deve conter ao menos uma atividade. Para tanto, fez-se o levantamento de quantas atividades constavam em cada seção, excluindo-se da análise a seção "Autoavaliação", que se encontra no final de cada unidade didática. O Gráfico 3 apresenta os dados levantados.

É possível observar no Gráfico 3 que, das 12 unidades didáticas, apenas uma apresenta a distribuição de pelo menos uma atividade para cada seção (aula 9), conforme a recomendação da literatura. O caso mais delicado ocorre na aula 12 , em que, das quatro seções temáticas, três não possuem atividades distribuídas. Fato pertinente é que, dos cinco casos apresentados em que as seções temáticas não corresponderam diretamente aos objetivos, dois não possuíam atividades e um terceiro possuía atividade, mas sem relação com o tema da seção. Apenas os dois restantes apresentavam atividades 
de acordo com as recomendações. Vale destacar que, embora a princípio corresponda a resultado negativo, a ausência da distribuição de atividades conforme recomendado não significa que o conteúdo de cada seção tenha sido negligenciado: uma possibilidade é as atividades correspondentes ao tema estarem agrupadas em outras seções ou a lacuna estar sendo suprida no final da unidade didática, na seção individual "Autoavaliação". Essas questões serão aprofundadas no subtópico "Atividades de aprendizagem e autoavaliação".

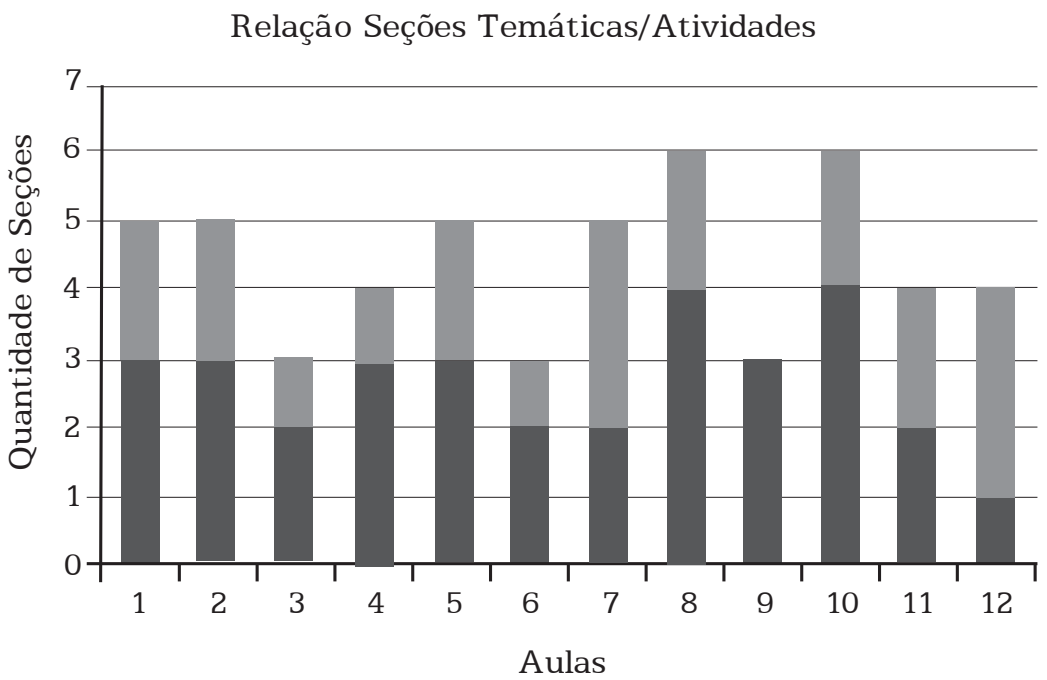

— Quantidade de seções com atividades

- Quantidade de seções sem atividades

\section{Gráfico 3 - Seções Temáticas com e sem Atividades no Corpus}

Fonte: Elaboração própria.

\section{Objetivos de aprendizagem}

Os objetivos, de modo geral, indicam algo que se deseja alcançar, material ou imaterial. Os objetivos pedagógicos, além de estabelecerem as prioridades do conteúdo a ser apresentado, definem aquilo que o aluno deverá ser capaz de realizar ao final de seus estudos. Em um MDI, os objetivos devem estar intrinsecamente relacionados tanto ao conteúdo apresentado quanto às atividades propostas no material, requisitando do aluno o trabalho com competências, estratégias e habilidades (Barreto et al., 2007). Eles contribuem, ainda, para promover a autoavaliação do aluno, a partir da identificação dos conteúdos que ele já domina, além de servirem como ponto de partida para a mediação pedagógica (Preti, 2010). 
Filatro e Cairo (2015) destacam estudos como a taxonomia dos objetivos educacionais, de Bloom; a aprendizagem baseada em competências; e a tipologia de Gagné para tratar da formulação dos objetivos. Em resumo, pode-se dizer que estes devem ser redigidos de forma clara, contendo uma descrição do comportamento esperado do aluno e das condições em que se deseja que esse comportamento seja demonstrado (Preti, 2010). Da mesma forma, devem ser utilizados verbos que evoquem uma ação específica, com termos precisos, uma vez que os objetivos devem tratar de elementos mensuráveis e verificáveis (Barreto et al., 2007).

Para a análise dos objetivos do material Geografia da População (Dantas; Morais; Fernandes, 2011), optou-se, em primeiro momento, pelo levantamento de quantos objetivos foram empregados em cada unidade didática e dos verbos utilizados em sua redação, conforme mostra o Quadro 2.

\section{Quadro 2 - Detalhamento dos Objetivos Presentes no Corpus}

\begin{tabular}{|c|c|c|}
\hline Aula & Objetivos & Verbos \\
\hline 1 & 4 & Identificar, entender, refletir, compreender \\
\hline 2 & 3 & Descrever, entender, refletir \\
\hline 3 & 4 & Aplicar, explicar, compreender, entender \\
\hline 4 & 4 & Aplicar, relacionar, compreender, entender \\
\hline 5 & 3 & Compreender, entender, saber \\
\hline 6 & 4 & Identificar, relacionar, analisar, compreender \\
\hline 7 & 4 & Identificar, explicar ( $2 x)$, analisar \\
\hline 8 & 5 & Compreender $(2 \mathrm{x})$, refletir, entender, explicar \\
\hline 9 & 4 & Compreender $(2 \mathrm{x})$, discutir, entender \\
\hline 10 & 5 & Comparar, entender, compreender, discutir, analisar \\
\hline 11 & 4 & Conhecer, compreender, analisar, explicar \\
\hline 12 & 5 & Compreender, explicar (2x), analisar, discutir \\
\hline
\end{tabular}

Fonte: Elaboração própria.

Com média de quatro objetivos por aula, o corpus de análise apresenta, majoritariamente, verbos considerados de baixa precisão em sua redação. Dos 49 objetivos redigidos, apenas 13 (26\%) continham verbos considerados pela literatura como precisos, passíveis de verificação de forma não subjetiva.

Entre os verbos mais utilizados nos objetivos listados estão "compreender", empregado 12 vezes, e "entender", 8 vezes. Ambos os verbos admitem vasta gama de interpretações, sendo considerados 
imprecisos, de forma que seu uso não é recomendado. Isso ocorre por não ser possível "observar diretamente o acúmulo de conhecimento" (Barreto et al., 2007, p. 61), pois remetem a aspectos internos do aprendiz. Em contrapartida, outros verbos utilizados no material, como "identificar", "descrever" e "relacionar", são amplamente recomendados, por serem facilmente verificados a partir de atividades práticas.

Embora em primeira análise os objetivos careçam de adequações aos estudos pedagógicos, indagou-se aos alunos sobre a clareza e a conexão dos objetivos relacionados em cada aula com seus respectivos temas. Como resultado, 88,9\% destacaram esses aspectos positivamente, enquanto apenas $11,1 \%$ os consideraram de forma negativa. Isso significa que a maioria dos alunos foi capaz de entender o que se esperava como resultado em cada um dos objetivos, independentemente do verbo utilizado em sua redação.

\section{Atividades de aprendizagem e autoavaliação}

Antes de formular as atividades e as avaliações pelas quais o aluno deverá passar em seus estudos, é preciso ter clareza da função desses recursos na formação do indivíduo. Entende-se que, "por meio das atividades, o estudante põe em jogo seus recursos, estratégias e habilidades e participa ativamente do processo de construção do seu saber" (Preti, 2010, p. 141). Ao se tratar de MDI para a EaD, é preciso ter em mente que as atividades de aprendizagem devem funcionar não apenas como um verificador, ao final de uma disciplina, mas como uma estratégia que apoie o aluno no processo de ensino e aprendizagem, sendo parte constante da formação dele (Preti, 2010).

A recomendação para o desenvolvimento do MDI é de que as atividades sejam distribuídas de maneira uniforme no material, cobrindo os conteúdos principais de cada seção temática, além de estarem intrinsecamente relacionadas, uma a uma, a um ou mais objetivos definidos em cada seção do material (Barreto et al., 2007). De acordo com Preti (2010), atividades são proposições ao estudante de reflexões, exercícios, estudos de caso, coletas de dados ou breves pesquisas.

Já as autoavaliações buscam constatar se as informações foram assimiladas pelo aluno, permitindo a verificação imediata da compreensão dos temas e a avaliação do alcance dos objetivos propostos para aquela unidade, lembrando que, segundo Barreto et al. (2007), estes devem apresentar nítida ligação com as atividades, a fim de garantir a integridade educacional do material.

A partir desses dados, foi proposta a análise das atividades encontradas no corpus da pesquisa - as quais totalizaram 38, em conjunto com outras 38 questões apresentadas na seção "Autoavaliação", ao final de cada aula. No Quadro 3, expõem-se os dados referentes à relação direta entre as atividades e autoavaliações propostas e os objetivos dados para cada aula. 


\section{Quadro 3 - Detalhamento das Atividades e Autoavaliações do Corpus}

\begin{tabular}{|c|c|c|c|c|c|c|}
\hline Aula & Seções & Objetivos & Atividades & $\begin{array}{c}\text { Objetivos } \\
\text { contemplados }\end{array}$ & Autoavaliações & $\begin{array}{c}\text { Objetivos } \\
\text { contemplados }\end{array}$ \\
\hline 1 & 5 & 4 & 4 & 1 e 3 & 3 & 1,3 e 4 \\
\hline 2 & 5 & 3 & 3 & 3 & 2 & 2 e 3 \\
\hline 3 & 3 & 4 & 3 & 1,2 e 3 & 1 & 3 e 4 \\
\hline 4 & 4 & 4 & 3 & 3 e 4 & 3 & 3 e 4 \\
\hline 5 & 5 & 3 & 3 & Todos & 6 & Todos \\
\hline 6 & 4 & 4 & 3 & 2 e 3 & 3 & 2 e 3 \\
\hline 7 & 5 & 4 & 3 & 1,2 e 3 & 2 & Todos \\
\hline 8 & 6 & 5 & 4 & 1,3 e 4 & 4 & 3 \\
\hline 9 & 3 & 4 & 4 & Todos & 4 & 2,3 e 4 \\
\hline 10 & 6 & 5 & 4 & 4 & 4 & 1,3 e 4 \\
\hline 11 & 4 & 4 & 2 & 1,2 e 3 & 3 & 2 e 3 \\
\hline 12 & 4 & 5 & 2 & 1,2 e 5 & 3 & 1,3 e 4 \\
\hline
\end{tabular}

Fonte: Elaboração própria.

Com base no Quadro 3, além da apresentação de uma nova visualização dos dados acerca da relação entre seções temáticas e número de atividades (a partir da inclusão das colunas 2 e 4), pode-se afirmar que as atividades não contemplam todos os objetivos propostos para cada aula (colunas 4 e 5), sendo completadas, a princípio, pelas atividades de autoavaliação (colunas 6 e 7). Ainda assim, em alguns casos, nem todos os objetivos foram contemplados de forma direta pelo somatório das atividades, conforme se observa no Gráfico 4. O objetivo "Aplicar as teorias populacionais para a análise de uma situação-problema" (Dantas; Morais; Fernandes, 2011, p. 43), por exemplo, é inserido, mas não são apresentadas atividades que permitam a prática de tais comandos, embora haja a parte informacional no conteúdo. O mesmo ocorre em outros pontos do material, indicando a necessidade de uma nova revisão, em especial da tríade objetivos-conteúdo-atividades.

Relação Objetivos/Atividades

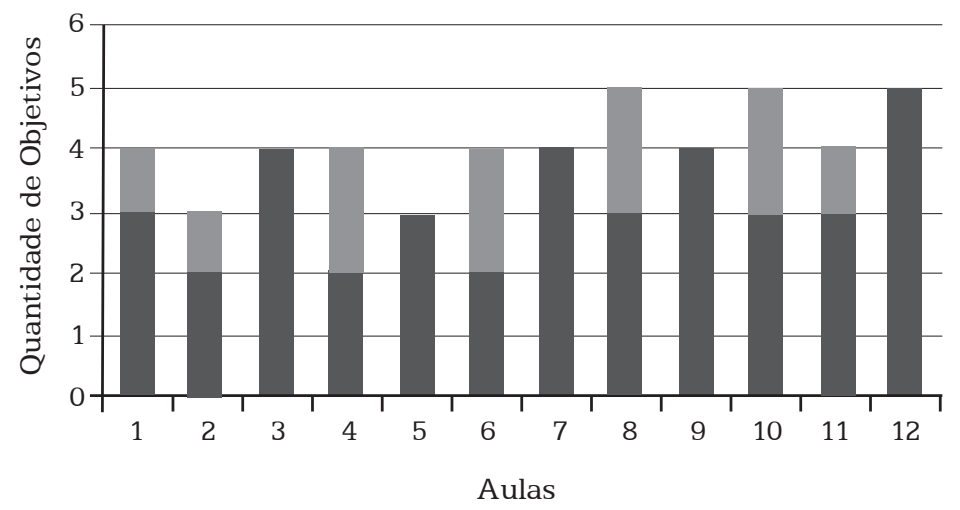

ص Quantidade de objetivos contemplados pelas atividades

n Quantidade de objetivos não contemplados pelas atividades

\section{Gráfico 4 - Objetivos Contemplados e não Contemplados pelas Atividades no Corpus}

Fonte: Elaboração própria. 
Verifica-se que apenas em 5 das 12 aulas o somatório das atividades com as autoavaliações foi capaz de contemplar todos os objetivos relacionados às aulas (aulas 3, 5, 7, 9 e 12), correspondendo a $41 \%$ do total. Ainda, em duas aulas, apenas $50 \%$ dos objetivos propostos foram contemplados pelo somatório das atividades (aulas 4 e 6). Com efeito, faz-se necessário reforçar que, embora os objetivos não tenham sido abrangidos em sua totalidade nas atividades, isso não significa que o conteúdo disposto nas seções de estudo do MDI Geografia da População não tenha atendido a esses objetivos. Como exposto anteriormente, as seções temáticas também possuem relação direta com os objetivos indicados.

Depois da análise, julgou-se pertinente perguntar aos alunos se eles foram capazes de resolver as atividades propostas com base apenas no conteúdo didático apresentado no material. Essa questão buscou verificar se havia alguma lacuna de informação, aprofundando a análise sobre as atividades presentes no corpus. Como resultado, 66,7\% dos alunos afirmaram que as atividades atenderam a esse requisito, enquanto 33,3\% indicaram não terem sido capazes de concluir as atividades sem recorrer a outras fontes de informação.

Cabe ressaltar que, embora a adequação das atividades aos objetivos tenha sido o foco da análise neste trabalho, a qualidade do desenvolvimento de cada atividade é temática frutífera, sendo aprofundada em outro trabalho cuja análise tem como base a Teoria da Carga Cognitiva.

\section{Boxes de elementos periféricos}

Em geral, a finalidade dos boxes de elementos periféricos nos MDIs é apresentar possíveis desdobramentos do conteúdo principal do material, facultando ao aluno o aprofundamento ou a extrapolação dos tópicos de estudo, valorizando sua autonomia (Barreto et al., 2007).

A utilização dos boxes e a seleção dos conteúdos periféricos para o conteúdo principal fazem parte da organização da arquitetura da informação do material. A recomendação mais importante para a inserção dos boxes é o favorecimento da possibilidade do desdobramento múltiplo do conteúdo, sem que se desfaça a fluidez da linha de raciocínio principal (Barreto et al., 2007).

Os boxes podem ser classificados de acordo com os recursos apresentados, sendo as finalidades mais comuns a ênfase, a explicação expandida, o dicionário, a informação de curiosidade e a conexão com outras mídias. Também são frequentes as indicações de reflexão, os conceitos, os questionamentos e a retomada de conteúdos (Barreto et al., 2007; Preti, 2010).

Em Geografia da População (Dantas; Morais; Fernandes, 2011) foram utilizados diversos boxes periféricos, totalizando 25 itens, porém o material não contou com a divisão clara dos tipos de boxes, indicada por título ou ícone, sendo necessária a leitura na íntegra dos itens para a compreensão da finalidade de cada um. Para os fins desta pesquisa, foi 
proposta a seguinte classificação, depois da análise dos recursos de cada boxe: atenção, biografia, conceito, relembrando, saiba mais e reflexão. Há, também, ocorrências de destaque de termos dentro do texto, negritados e em cor distinta, que se entendeu como indicação de boxes do tipo verbete. O Quadro 4 mostra um delineamento dos boxes encontrados no material.

\section{Quadro 4 - Detalhamento dos Boxes Utilizados no Corpus}

\begin{tabular}{|c|c|c|l|}
\hline Aula & Seções & Boxes & \multicolumn{1}{|c|}{ Classificação dos boxes } \\
\hline 1 & 5 & - & - \\
\hline 2 & 5 & 3 & Biografia, reflexão, saiba mais \\
\hline 3 & 3 & 5 & Biografia, reflexão, verbete (3x) \\
\hline 4 & 4 & 1 & Conceito \\
\hline 6 & 5 & 4 & Relembrando, saiba mais (3x) \\
\hline 7 & 4 & 2 & Saiba mais, relembrando \\
\hline 9 & 5 & 2 & Saiba mais (2x) \\
\hline 10 & 6 & 2 & Saiba mais, verbete \\
\hline 11 & 4 & - & - \\
\hline 12 & 4 & 4 & Atenção, conceito, saiba mais, relembrando \\
\hline 9 & 4 & 5 & Saiba mais (2x), atenção (3x) \\
\hline
\end{tabular}

Fonte: Elaboração própria.

A partir do Quadro 4, observa-se que o tipo de boxe mais utilizado no corpus de análise foi o "saiba mais", correspondendo a 11 (44\%) das 25 (100\%) ocorrências. Entenderam-se como "saiba mais" os boxes cujo conteúdo aprofundava o conteúdo principal da unidade didática em questão. Com relação às demais ocorrências, três outros tipos de boxes chamaram atenção, dada a maneira como foram utilizados: "relembrando", "verbete" e "conceito". Dos três "relembrando" (aulas 5, 6 e 10), apenas um de fato apresentava o conteúdo a ser retomado (aula 5), enquanto os outros dois indicavam que o aluno retornasse às aulas anteriores para rever os conteúdos.

Quanto às quatro ocorrências do boxe "verbete", apenas uma delas consistia em uma explicação do termo destacado (aula 8), enquanto as demais funcionavam como indicações de leituras complementares, recomendadas para o aprofundamento dos estudos. Por fim, uma das ocorrências do boxe "conceito" não foi utilizada de forma periférica (aula 4), sendo sua leitura obrigatória para o entendimento do restante da aula. Cabe ressaltar que em duas aulas (aula 1 e aula 9) não houve a utilização de quaisquer desses recursos. Ademais, não foram identificados boxes do tipo multimídia, contendo indicações de outras mídias, como filmes, sites e jogos. 
Completando os dados obtidos sobre o recurso dos boxes no material, foi perguntado aos alunos se sua aplicação foi favorável ao processo de ensino e aprendizagem, auxiliando os estudos e permitindo melhor entendimento do conteúdo principal. Como resultado, 88,9\% destacaram os boxes positivamente, enquanto apenas $11,1 \%$ os consideraram de forma negativa. Embora presentes no material, os boxes parecem não ser utilizados em sua totalidade da forma mais apropriada por essa mídia, conforme preconiza a literatura, não respeitando suas classificações e objetivos, como visto anteriormente. Contudo, ao considerar a relação estabelecida entre os alunos, os boxes utilizados parecem cumprir ao menos dois de seus papéis principais: a conceituação de termos específicos e o desdobramento dos conteúdos extras, facilitando a aprendizagem.

\section{Linguagem no MDI: características dialógicas}

Além da arquitetura da informação e da divisão em unidades didáticas e seções temáticas, um dos elementos de grande importância ao se desenvolver um material voltado para a EaD é a linguagem utilizada, que deve ser sempre dialógica. Como aluno e professor estão separados espaçotemporalmente, o momento da idealização do material, feita pelo professor, é dissociado do momento da recepção do aluno, diferentemente do que ocorre na modalidade presencial. Logo, para que sejam amenizadas essas distâncias, o aluno precisa "ouvir a voz" do professor mediante o texto lido, os exemplos dados e as analogias feitas, de forma que ele também seja inserido no discurso didático (Horn, 2014), estimulado a refletir sobre o conteúdo e a atuar na construção de seu próprio conhecimento.

Destaque é dado ao dialogismo e à interação verbal (Bakhtin, 2006). Essa interação dialógica, chamada de diálogo didático, faz-se, no caso do MDI, por meio do suporte midiático desse material. Tem-se um diálogo didático simulado e assíncrono. Nesse tipo de comunicação, a relação está contida no próprio texto, cuja interpretação é feita pelo aluno em um momento posterior ao do registro no suporte midiático, no caso o MDI, que, por sua vez, ocorre no momento de seu desenvolvimento. Pode-se dizer, em contraste, que o diálogo entre o professor e o aluno em sala de aula se trata de um diálogo real (em oposição ao "simulado") e síncrono. É importante ressaltar que, ao desenvolver um MDI para a EaD, busca-se tanto quanto possível simular o diálogo real que existiria entre professor e aluno em um contato síncrono, favorecendo, com isso, o sentimento de que há uma relação pessoal entre os atores do processo de ensino e aprendizagem, ainda que a distância (Filatro; Cairo, 2015).

Nesse sentido, recomenda-se o uso de uma linguagem que se distancie do discurso acadêmico, ficando em um intervalo entre o discurso científico moderado e o narrativo oral (Horn, 2014). Ligadas às questões semânticas do texto, Preti (2010) traz algumas considerações, como empregar estruturas de enumeração e sequências, analogias, comparações e exemplos para melhor entendimento do conteúdo; uso de objetivos claros e resumo 
introdutório; frases curtas e uso de no máximo duas ideias por parágrafo. Esses recursos dão maior interpretatividade ao texto, pois permitem e facilitam a interação do leitor com ele, conforme evidenciam Damiana e Pena (2016).

Três perguntas foram feitas aos alunos no que tange a tipo de linguagem adotado no material, quantidade de exemplos apresentados e vocabulário técnico empregado. Sobre a clareza e a objetividade da linguagem adotada, além do estímulo à reflexão crítica, 77,8\% dos alunos julgaram-na adequada. Com relação à quantidade de exemplos dados para a explicação dos conteúdos, 88,9\% acharam-na satisfatória, enquanto $11,1 \%$, insuficiente.

No que se refere ao vocabulário técnico, a pergunta aos alunos foi se houve explicação clara dos termos. Como resposta, 88,9\% afirmaram terem sido explicados de forma efetiva, contra 11,1\% que discordaram. Entretanto, evidência pertinente foi encontrada ao se questionar os alunos sobre os elementos ausentes no material que, caso presentes, os ajudariam a aprimorar os estudos. Nessa questão, 33,3\% apontaram o glossário como item relevante e ausente, embora apenas 11,1\% tenham percebido a explicação dos termos técnicos como insatisfatória, complementando e ratificando a questão apresentada.

\section{Imagens e recursos gráficos}

Um dos aspectos da valorização do potencial multimídia do MDI implica o uso de imagens e recursos gráficos diversos. Esses recursos devem ser utilizados de forma didática, e não meramente ilustrativa, em complemento aos textos verbais ou buscando apresentar a informação em formato mais adequado ao que se pretende explicar, como gráficos, quadros, tabelas, quando pertinentes. Preti (2010) destaca que, ao optar pelo uso de uma imagem, deve-se empreender uma série de questionamentos: se a imagem motiva o leitor, se traduz ideia ou conceito importante, se torna o texto verbal mais claro, se resume ou identifica uma informação e, em caso de atividades, se a imagem utilizada auxilia o aluno na realização do que foi proposto. Entre as categorias possíveis de imagens e recursos gráficos, as de maior recorrência nos diversos MDIs são: diagramas, fluxogramas, fotografias, ícones, ilustrações, infográficos, mapas, quadros e tabelas (Preti, 2010).

Filatro e Cairo (2015) pontuam que, visando à relevância pedagógica no MDI, é fundamental que as imagens venham acompanhadas de breves textos descritivos ou legendas, direcionando a atenção do aluno para elementos pontuais e esclarecendo determinadas especificidades. Contudo, cabe ressaltar que, no gênero MDI, "a linguagem não verbal precisa estar em conexão com a linguagem verbal com a finalidade de produzir maior possibilidade de interpretação por parte do leitor" (Damiana; Pena, 2016, p. 4), e sua função, via de regra, é elucidar ou aprofundar o texto, não substituí-lo por completo. 
Para a análise do corpus, foram excluídos da contagem os elementos inerentes ao projeto gráfico do material, quais sejam: as imagens de abertura das unidades didáticas e das seções temáticas. Destaca-se que o projeto gráfico não conta com o uso de ícones para sinalização de seções ou boxes periféricos, como recomendado por Preti (2010).

Em um primeiro momento, fez-se o levantamento da quantidade de imagens utilizadas por unidade didática e sua possível categorização, com base na natureza da informação veiculada. A partir desse levantamento, sugeriu-se a seguinte categorização para as imagens presentes no material: fotografia, gráfico, ilustração, mapa, quadro e tabela. A sugestão foi feita porque no interior do corpus não há padrão de categorização com legenda indicativa, constando esta, na maioria das vezes, apenas em quadros e tabelas, sendo as demais ocorrências tratadas como "figuras". O Quadro 5 detalha a quantidade de imagens existente por unidade didática e suas categorizações.

\section{Quadro 5 - Detalhamento das Imagens Presentes no Corpus}

\begin{tabular}{|c|c|c|c|}
\hline Aula & Imagens & \multicolumn{1}{|c|}{ Categorização } \\
\hline 1 & 4 & 2 fotografias, 1 ilustração, 1 mapa \\
\hline 2 & 2 & 1 fotografia, 1 ilustração \\
\hline 3 & 0 & - & 1 gráfico, 2 ilustrações \\
\hline 5 & 3 & 4 gráficos, 1 ilustração, 2 mapas \\
\hline 6 & 7 & 2 fotografias, 2 ilustrações, 3 mapas \\
\hline 7 & 7 & 1 fotografia, 1 ilustração, 4 mapas \\
\hline 8 & 10 & 1 gráfico, 6 mapas, 3 quadros \\
\hline 9 & 9 & 2 ilustrações, 3 mapas, 4 tabelas \\
\hline 10 & 11 & 7 gráficos, 1 ilustração, 2 mapas, 1 tabela \\
\hline 11 & 7 & 4 fotografias, 1 ilustração, 1 mapa, 1 tabela \\
\hline 12 & 6 & 3 gráficos, 1 ilustração, 2 tabelas \\
\hline
\end{tabular}

Fonte: Elaboração própria.

A partir do Quadro 5, observa-se que o uso de imagens não segue um padrão: ora nenhum tipo de imagem foi utilizado (aula 3) ora 11 foram empregadas na mesma unidade didática (aula 10). Salienta-se que, para esse levantamento, foi utilizada como artifício a contagem dos elementos tendo como base o número de legendas encontradas no material, sendo os grupos de imagens (como gráficos e mapas dispostos em forma de mosaico) contados apenas uma vez, quando situados sob a mesma legenda, como exemplifica a Figura 1. 

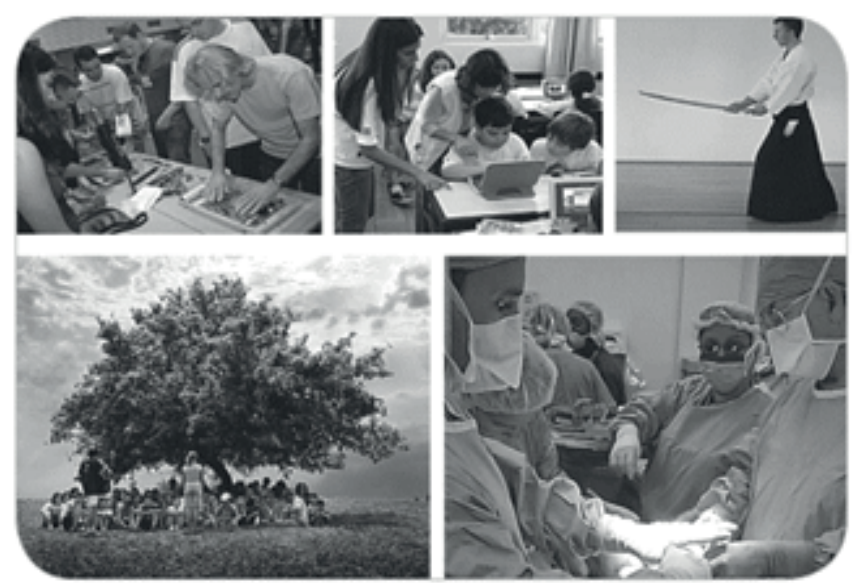

Figura 1 - Mosaico de Fotografias sob a mesma Legenda

Das 72 imagens, foram utilizadas 10 fotografias, 16 gráficos, 13 ilustrações, 22 mapas, 3 quadros e 8 tabelas. Como o material em questão versa sobre o tema "geografia da população", o uso amplificado de mapas era esperado, sendo considerado satisfatório. A maioria das imagens e recursos gráficos atendeu aos propósitos didáticos das seções temáticas, excetuando-se as classificadas como ilustrações. ${ }^{1}$ Das 13 ilustrações utilizadas, nenhuma trazia relação direta com a seção em que se apresentava: trata-se de duas personagens, uma coruja e uma cobra, aparentemente desenvolvidas para o material. O propósito do uso dessas ilustrações não fica claro no projeto gráfico, de forma que surge a hipótese de se tratar apenas da tradução do aspecto lúdico, conforme a Figura 2.

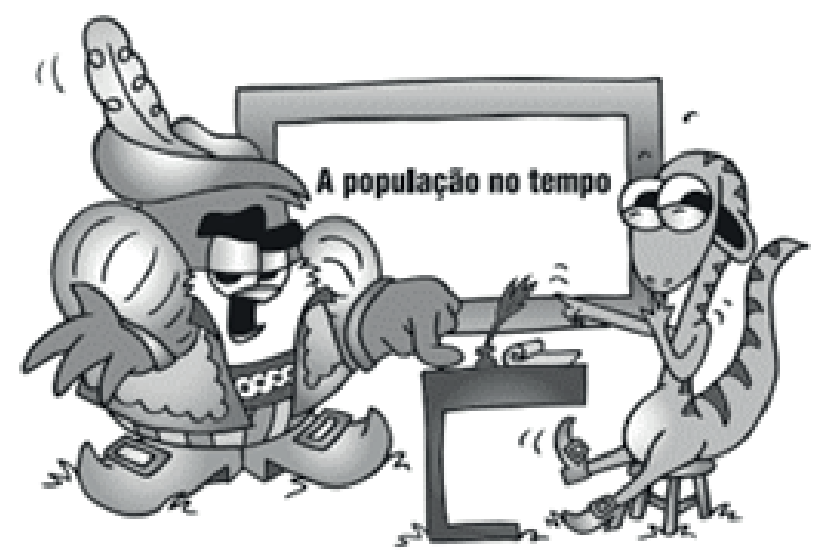

Figura 2 - Ilustração Lúdica

Fonte: Dantas; Morais; Fernandes (2011, p. 15).

Ilustrações aqui são imagens criadas por um profissional da ilustração; no caso do material em questão, apresentando um personagem.
Procurando ratificar a avaliação de bom uso das imagens no material, os alunos foram indagados sobre a eficácia das imagens e dos gráficos utilizados. Como resultado, 88,9\% julgaram que esses recursos ajudaram na 
compreensão dos conceitos apresentados e 11,1\% discordaram. Conclui-se que, no geral, os recursos imagéticos foram bem empregados no material, produzindo significado e corroborando a apreensão do sentido daquilo que é exposto no plano informacional trazido pelo material impresso.

\section{Considerações finais}

A EaD, em grande parte de sua trajetória, parece ter servido a uma proposta mais informacional, e esse tipo de escolha metodológica acaba por carregar consigo um paradigma educacional de transmissão do conhecimento. Hoje, busca-se desconstruir esse paradigma, voltando os esforços da EaD para a formação autônoma do indivíduo, favorecendo a construção da aprendizagem, a reflexão e o pensamento crítico. Nesse cenário, o processo de design educacional ganha espaço, indicando novos caminhos possíveis para que esse objetivo seja alcançado.

Desenvolver MDI é um desafio, porque, além de possibilitar em suas linhas e entrelinhas as nuances do dialogismo, adentra a própria configuração das concepções do material em si, que não pode ser destituído das prerrogativas da educação dentro de um mundo globalizado e tecnológico, nem deixar de traduzir um processo de aprendizagem do aluno que passa pela produção de sentidos. E esse material mediacional que vai cumprir o papel de intermediar as relações de construção do conhecimento do enunciatário ante o enunciador, estabelecendo uma relação de diálogo, parceria, não de poder e submissão.

Percebe-se que a literatura especializada reforça tais questões, orientando os profissionais envolvidos no processo de desenvolvimento de MDI a utilizar as potencialidades dessa mídia para oportunizar uma experiência educacional eficaz, eficiente e motivadora pedagogicamente. Embora carente de adequações quanto ao que preconiza a literatura especializada, observou-se, ao longo da pesquisa, que o MDI Geografia da População (Dantas; Morais; Fernandes, 2011) satisfez os alunos, que julgaram a experiência com o material de forma positiva, na maioria dos elementos sobre os quais foram questionados.

Com relação aos recursos educacionais do material, a análise feita pelos alunos foi satisfatória, indicando que houve a facilitação do processo de ensino e aprendizagem, com destaque para os boxes periféricos e a linguagem adotada. Quanto ao design educacional do MDI, embora haja lacunas na relação do trio objetivos-atividades-conteúdo, a dupla objetivosconteúdo atendeu satisfatoriamente à proposta: dos 49 objetivos listados no material, apenas 4 não foram contemplados pelas seções temáticas.

No que diz respeito à dupla objetivos-atividades, embora as autoavaliações complementem as atividades principais do material, esse quesito não obteve indicação satisfatória, uma vez que em apenas 5 das 12 unidades há atividades que contemplam todos os objetivos propostos, ainda que haja a possibilidade de o aluno alcançá-los com o conteúdo apresentado na unidade. O conhecimento é informado pelos objetivos, trabalhado no conteúdo, mas não praticado. 
Nesse sentido, há a necessidade de maior entrosamento entre esses itens, a fim de que seja mantida a integridade educacional do material. Para uma próxima versão do material, sugere-se a leitura cautelosa do trio objetivos-conteúdos-atividades, a fim de garantir que todos os objetivos propostos sejam contemplados. As atividades sugeridas no material devem funcionar como degraus para que o aluno, depois do estudo dos conteúdos, possa chegar aos objetivos.

Além disso, será positiva ao MDI em questão a inclusão de elementos, como boxes multimídia, com a indicação de filmes, sites e jogos complementares ao conteúdo, promovendo o diálogo com outras mídias. Assim, o MDI cumprirá sua função, saindo de um democratismo circunscrito a um universo de profissionais e servindo, realmente, de voz a quem o recebe.

\section{Referências bibliográficas}

\section{ASSOCIAÇÃO BRASILEIRA DE EDUCAÇÃO A DISTÂNCIA (ABED).}

Relatório analítico da aprendizagem a distância no Brasil 2014.

Curitiba: Abed; Ibpex, 2015. Disponível em: <http://www.abed.org.br/ censoead2014/CensoEAD2014_portugues.pdf>. Acesso em: 11 jul. 2016.

ANUÁRIO Brasileiro Estatístico de Educação Aberta e a Distância 2007. 3. ed. São Paulo: Instituto Monitor, 2007. Disponível em: <http://www. abraead.com.br/anuario/anuario2007.pdf > Acesso em: 11 jul. 2016.

BAKHTIN, M. Marxismo e filosofia da linguagem. Tradução: Michel Lahud. São Paulo: Hucitec, 2006.

BARRETO, C. C. et al. (Org.). Planejamento e elaboração de material didático impresso para educação a distância. Rio de Janeiro: Fundação Cecierj, 2007.

BARRETO, C. C. Ambientação em Novas Tecnologias. Rio de Janeiro: SESI; UFF, 2012. v. 1.

BELISÁRIO, A. Desafios da produção de material didático para a educação a distância. In: FIDALGO, F. S. R. et al. (Org). Educação a distância: meios, atores e processos. Belo Horizonte: UFMG, 2013. v. 1.

BRASIL. Ministério da Educação (MEC). Referenciais de qualidade para a educação superior a distância. Brasília: Secretaria da Educação a Distância, 2007. Disponível em: <http://portal.mec.gov.br/seed/ arquivos/pdf/legislacao/refead1.pdf >. Acesso em: 11 jul. 2016. 
CHOPPIN, A. História dos livros e das edições didáticas: sobre o estado da arte. Educação e pesquisa, São Paulo, v. 30, n. 3, p. 549-566, set./dez. 2004.

DAMIANA, B.; PENA, A. L. Material didático para educação a distância: a linguagem em perspectiva dialógica. Artefactum: Revista de estudos em Linguagens e Tecnologia, [online], v. 1, n. 1, 2016. Disponível em: $<$ http://artefactum.rafrom.com.br/index.php/artefactum/article/ view/980/595>. Acesso em: 11 jul. 2016.

DANTAS, E. M.; MORAIS, I. R. D.; FERNANDES, M. J. C. Geografia da população. 2. ed. Natal: Ed. da UFRN, 2011.

FILATRO, A. Design instrucional na prática. São Paulo: Pearson Education do Brasil, 2009.

FILATRO, A.; CAIRO, S. Produção de conteúdos educacionais. São Paulo: Saraiva, 2015.

FIORIN, J. L. Linguagem e ideologia. 8. ed. São Paulo: Ática, 2007.

HORN, V. A linguagem do material didático impresso de cursos a distância. Revista da Faeeba: Educação e Contemporaneidade, Salvador, v. 23, n. 42, p. 119-130, jul./dez. 2014.

PRETI, O. Produção de material didático impresso: orientações técnicas e pedagógicas. Cuiabá: UAB/UFMT, 2010. (Coletânea Educação a Distância).

TRIMER, R. Livros e apostilas na EAD. In: LITTO, F. M.; FORMIGA, M. (Orgs.). Educação a distância: o estado da arte. São Paulo: Pearson Education do Brasil, 2012. p. 311-318. v. 2.

Recebido em 26 de outubro de 2016.

Solicitação de correções em 26 de junho de 2017.

Aprovado em 28 de julho de 2017. 